\title{
Effect of Hydration Status of School Children on Cognitive Performance and Impact of Health Education on Their Drinking Behavior
}

\author{
Hend Samy Ibrahim
}

Public health and Community Medicine, Faculty of Medicine, Cairo University

Submitted:30-06-2020 Revised:15-07-2020 Accepted:15-07-2020

\begin{abstract}
Background Dehydration among school children is highly prevalent. It has various negative health consequences in children, and it impairs cognitive performance. The figures of hydration status among Egyptian school children are scarce. Objectives: 1) Assess the prevalence of dehydration among school children. 2) Identify the effect of students' hydration status on cognitive function. 3) Determine the impact of health education on the students' drinking behavior, hydration status and cognitive abilities. Method: Pretest-posttest intervention study included $(n=180)$ students. Urine osmolality was tested to the students. Seven cognitive function tests were conducted measuring (visual attention, visual memory, short term memory, mathematical cognition and visuomotor skills). Providing drinking water education to the students then reassessment of urine osmolality and reapplying cognitive function tests. Results: Sixty eight percent of the students were dehydrated and was significantly decreased after health education to reach $47.8 \%$. The hydrated students performed significantly better than dehydrated in cognitive function tests except for reverse number recall and mathematical cognition where the improvement was shown to be significant. Urine osmolality was significantly negatively correlated with mean scores of cognitive function tests of (visual attention, forward number recall and line tracing). There was significant improvement in the cognitive function test after health education for letter cancelation, visual memory, forward number recall and mathematical cognition. Conclusions: Dehydration in highly prevalent among school children and have negative impact on cognitive performance. Health education to the students helped in improving drinking behavior and adopting healthy drinking water practices. Schools are encouraged to implement drinking water polices and rules.
\end{abstract}

Key words: Cognitive function, Hydration status, School children, Intervention study

Corresponding author: Hend Samy Ibrahim Mohamed Dr.hendsamy.com@hotmail.com.

\section{Introduction}

The largest component of human body is water. It supports almost all vital body functions and metabolic reactions. ${ }^{1}$

It is fundamental to maintain proper hydration in children and ensuring consuming adequate amount of water. ${ }^{2}$ The recommended daily water intake differs according to age, gender and widely varies between countries. According to the US
Institute of Medicine the recommended daily intake of total water is $2400 \mathrm{~mL} /$ day and $2100 \mathrm{~mL} /$ day for American boys and girls aged from 9 to 13 years respectively. ${ }^{3}$ The recommendations of the European Food Safety Authority are $2100 \mathrm{~mL} /$ day for boys and $1900 \mathrm{~mL} /$ day for girls aged 9 to 13 years. ${ }^{4}$ If the children don't meet their daily water requirement they will

$\begin{array}{llll}\text { Vol. } 39 & \text { No. } 2 & \text { April } & 2021\end{array}$


become dehydrated. $^{2}$

The dietary behaviors of children put them at a risk of dehydration which can lead to serious consequences on their health. They consume excessive soda, sugary beverages $^{5}$ and deficiency of water consumption. Children are vulnerable to increased water losses due to large surfaceto-mass ratio and immature volume or frequency of void which only reach their full maturity by adolescence. ${ }^{6}$

Dehydration among children and elevation of urine osmolality was shown to be highly prevalent in several countries with

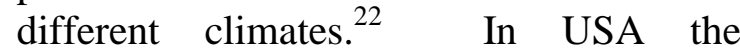
prevalence of dehydration among children aged between 6-10 years was 54\% ${ }^{39}$. In Los Angeles and New York City 63\% and $66 \%$ respectively of children had urine osmolality above 800 mosmol $/ \mathrm{kg}^{7}$ A study done in France reported that $62 \%$ of 9-11 years old children their urine osmolality was above $800 \mathrm{mosmol} / \mathrm{kg}$ and $22.7 \%$ was above $1.000 \mathrm{mosmol} / \mathrm{kg}^{22}$ In the MENA regions and particularly in Egypt the hydration status and fluid intake among school children still unknown and haven't been studied sufficiently. ${ }^{10,23}$ Although these regions have hot dry climate $^{2}$, high prevalence of fever and diarrheal diseases that can lead not only to dehydration but lethal electrolyte unbalance. $^{11}$

Cognitive ability of children is a complex process influenced by various factors. These factors include physiological status, practicing physical exercise, social support, nutrient intake, quality of sleep and socioeconomic level. ${ }^{40}$ Dehydration was shown to have a negative impact on the cognitive function and abilities of children. $^{24,28}$ Studies examining that relation were few; but it was depicted from intervention and descriptive studies that were conducted in different countries. ${ }^{12,13}$ Using repeated-measures design with school children, Benton \& Burgess ${ }^{24}$ found that short and long term memory of children was improved after water consumption when compared to those with no water consumption. Edmonds \& Burford ${ }^{28}$ study of 7-9-years old children in London schools showed that consuming water improved visual attention and visual memory where minimum amount of water can cause a significant effect on cognitive abilities. A study done among Italian school children ${ }^{33}$ assessing their base line hydration status using urine osmolality found that proper hydration associated with better performance in the auditory number memory task.

Mild dehydration which occurs when 2\% of the body weight lost as water can deteriorate short-term memory, mathematical ability, visuomotor and psychomotor skills ${ }^{14}$, but drinking water improved cognitive function ${ }^{20,24}$ ability to learn and concentration ${ }^{15,33}$.

This can be explained that dehydration leads to decrease in the volume of plasma and extracellular fluid causing brain hypoperfusion. Dehydration increases levels of stress hormones in blood as cortisol that have negative impact on cognitive function. ${ }^{16}$ Moreover dehydration is associated with reduction in the proliferation of neuronal cells which can be reversed with rehydration. ${ }^{17}$

Studies examined the relation between dehydration and cognitive function were subjected to limitations as lack of objective measurement for the hydration status, no assessment of the daily activity or base line hydration status ${ }^{12,28,35}$, also not taking into account weather contribution. The majority of intervention studies didn't determine the temperature of consumed water although it was proved to influence absorption of water. ${ }^{12,28,35}$ Pawson et al. ${ }^{42}$ found that drinking water improve the performance at exams, but they didn't 
measure the amount of consumed water. Most of the studies were conducted in controlled setting with no comparison of effect of the hydration status in real life tasks which is highly recommended.

Moreover studies used variety of measurements that don't take into account addressing of the confounding factors. ${ }^{41}$ Also these methods were not designed for nutritional interventions so they affect the of validity of the studies and lead to increase in the false negative results. ${ }^{29,31}$ Edmonds et al. ${ }^{12,28,35}$ recommended utilization of standardized measures which are sensitive to the nutritional interventions.

Adoption of drinking water habits is crucial especially in children as it will persist to adulthood ${ }^{18}$ and they will become role models for their offspring ${ }^{19}$. School environment, polices and regulations play a fundamental role in acquiring healthy habits. As for water intake it was shown that schools that encourage water intake (i.e., by ensuring water accessibility, proper water fountains, and providing health education), water consumptions among the students was more than schools that lack supportive regulations and infrastructure. ${ }^{20,9}$

Improving drinking behavior among children can be a continuous fruitful strategy for the health risks prevention. ${ }^{21}$ This study aimed to assess the prevalence of dehydration among the school children, second identify the effect of students' hydration status on cognitive function and then determine the impact of health education on the students' drinking behavior, hydration status and cognitive ability.

\section{Method}

The study was a school based pretestposttest intervention study, conducted at an elementary school in Giza, Egypt.
The study was done in the academic year 2018-2019. It included exploratory, pretest, intervention and posttest phases.

A convenient non probability sample of 180 students (aged 9-11 years old ) including all those who agreed to participate in the study .Any student with health problem affecting water balance was excluded for example gastro intestinal problems diarrheal diseases, vomiting, kidney, liver diseases or diabetes.

1- Exploratory and pretest phase.

A) Observation of the school environment regarding the structure and quality of drinking water system. The researcher walked around the school buildings accompanied by the school secretary to observe the availability, accessibility and number of functioning drinking water sources guided by an adapted standardized instrument that was developed in previous studies. ${ }^{46}$ The researcher assessed the quality of water regarding the location, type, functional status and the cleanliness appearance (e.g., mold, debris in basin). Beside the toilets the school had one large water basin with three fountain taps only two of them were functioning .The basins were not clean, filled with stagnant water, growing molds and floating particles.

B) Focus group discussion was done with seven teachers .It included questions about their perception regarding the school drinking water facilities, drinking habits of the students and barriers facing them in drinking water at school, the teachers were asked about their ideas for improvements.

C) Measuring students' urine osmolality: Urine osmolality determine the amount of particles of solute (in milliosmoles) within every kilogram of urine, the more the urine osmolality the poor hydration. ${ }^{26,7}$

Dehydration is excessive loss of water from the body. The degree of urine osmolality (Uosm) of 800 mosm $/ \mathrm{kg} \mathrm{H}_{2} \mathrm{O}$ was taken a cutoff point to categorize the 
children in two groups below 800 $\mathrm{mosm} / \mathrm{kg} \mathrm{H}_{2} \mathrm{O}$ were the hydrated group, and above $800 \mathrm{mosm} / \mathrm{kg} \mathrm{H}_{2} \mathrm{O}$ were the dehydrated group ${ }^{27}$.

The test was done over a period of ten days by the researcher and three assistants. The students were divided into twelve groups each group included 15 students.

First it was agreed with a medical laboratory to conduct urine osmolality analysis for the students. The lab technician was attending at 1:00 PM to take the urine samples in labeled containers and deliver them to the lab according to the standardized protocols.

D) Cognitive tests.

After urine analysis, the students were asked to answer seven cognitive function tests. The tests were adapted from previous studies ${ }^{12,13,28}$. They were designed to test the cognitive skills which were known to be affected by hydration ${ }^{13,28}$. First the tests were translated in Arabic and were pilot tested on one group to determine time taken to answer, difficulty and to develop the appropriate instructions. These tests included: 1. Cancellation of letters (visual attention): Students were asked to cross out the targeted letters which were randomly distributed among a network of non-target letters. The score was calculated through the number of valid characters that were crossed out subtracted from the number of invalid characters. This test took one minute (The maximum score was 38). 2. Find the difference between two images (visual attention): Students were asked to detect and circle the dissimilarity between two identical images. The score was calculated by adding the number of correct circles and subtracting from the number of incorrect circles. This test took one minute (The maximum score was 11). 3. Indirect image difference (visual memory): First the students were given an image to look at for only one minute then another image nearly similar and the student were asked to circle the dissimilarity found between the two images in a given time of one minute. The score was calculated by adding the numbers of correct circles and subtracting it from the incorrect circles number (The maximum score was 9).

4. Forward number recall (short-term memory): Two to six numbers forming ten sequences were read aloud. The students wrote each sequence after hearing it. The score was the total number of correct sequences (The maximum score was 10 ).

5. Reverse digit recall (short-term memory): Two to five numbers forming eight sequences were read aloud. The students were asked to write each sequence after they heard it but in reversed order. The score was calculated by adding the total number of correct sequences (The maximum score was 8)

6. Adding numbers (mathematical cognition). The students were given 60 adding problems of one or 2 digits in $2 \mathrm{~min}$ .That was to measure their speed of perception in mathematical calculations. The score was the number of problems answered correctly (The maximum score was 60).

7. Line tracing (visuomotor skills): the students were given 15 seconds to draw a line between two lines which were curved and parallel. The score was calculated by measuring the distance of the line drawn in centimeters subtracted from the number of times where the drawn line touched the sides (The maximum score was 29).

\section{2- Implementation phase}

It was scheduled with the head of the school to conduct health education sessions to the sampled students and arrangement of the place with the required facilities took place. The students were divided into ten groups and ten health education sessions were conducted in a period of three weeks. The health 
education session aimed to arouse the attention of students about benefits of drinking water over other beverages and soda drinks, number of cups of water they should drink every day and they were advised to bring their bottle of water daily at school. At the end of the sessions the students were free to ask their questions.

The researcher designed a poster about importance of drinking water and motivating the students to drink water during the school day. The posters were hanged on prominent areas in school to be viewed by the students from all directions. Then the researcher designed and distributed brochures among the students. It contained the same idea of the poster but additionally there was a calendar section where the students put the number of water cups they drank in a small box next to each day. Also it contained a line graph out line ( $\mathrm{x}$ axis represented days of the week and $\mathrm{Y}$ axis represented number of water cups),and the students trained to fill the graph every day and draw line joining the Table 1: Duration of the study phases

\begin{tabular}{|c|c|}
\hline Study phases & Duration \\
\hline 1- Exploratory phases & 2 weeks \\
\hline $\begin{array}{l}\text { a) Observation of the school environment including drinking water system and } \\
\text { focus group discussion with teachers }\end{array}$ & 4 Days \\
\hline b) Urine analysis and cognitive function test & 10 Days \\
\hline 2-Implementation phase & 7 weeks \\
\hline a) Health education sessions & 3 Weeks \\
\hline b) Distribution, follow-up of brochures and presentation of the video & 4 weeks \\
\hline $\begin{array}{l}\text { 3-Posttest } \\
\text { Urine examination and cognitive function tests }\end{array}$ & 10 days \\
\hline
\end{tabular}

\section{Statistical analysis}

Statistical analyses were done using SPSS software. Quantitative data were determined by means \pm standard deviation (SD), and qualitative data by percentages. The prevalence of dehydration (in which urine osmolality was $800 \mathrm{mOsmol} / \mathrm{L}$ ) was measured among the selected sample. Independent sample $t$ test was utilized to dots to follow up their water dinking behavior. They were asked to bring the brochure every day and the researchers with the assistance were checking them. The researcher developed an animated health education video showing importance of drinking water, frequency and amount of consumption as well as the hazards of not drinking. It was designed to be attractive and focus in 5 minutes. It was scheduled to be presented in the classes at morning two times a week for a period of four weeks.

\section{3- Post intervention}

Two months after the implementation phase another urine analysis test was done to the students to test the effect of health education on their hydration status. It was done in February so the weather temperature was nearly similar to the pretest, to exclude the effect of high summer temperature on the hydration status of the students. Cognitive function tests were also done with same arrangements as the pretest.

No. 2

April

2021 calculate the difference of the mean scores of cognitive function tests between the dehydrated and hydrated group .Person correlation analysis was done to evaluate the correlation between urine osmolality and mean cognitive function test scores. Paired t test was used for determining the difference in the mean scores and urine 
osmolality before and after health education. $\mathrm{P}$ value $<0.05$ was significant.

\section{Ethical consideration}

Before starting the study it was approved by the school administration team. According to the declaration of Helesiniki a consent letter was sent to all parents of the fifth and sixth grades students. The letter contained explanation of the study purpose, procedures As shown in the figure $68.3 \%$ of the studied students were dehydrated and $31.7 \%$ were hydrated. After provision of health education the percent of dehydrated students was decreased to reach $47.8 \%$ and that of hydrated students was increased $52.2 \%$.

and asking them if their child experienced recent vomiting, diarrhea, fever, taking medications suffering from diabetes or renal problems.

\section{Results}

Table 2: Comparison between mean score of cognitive function tests in dehydrated and hydrated students

\begin{tabular}{llrrrrr} 
& \multirow{2}{*}{ Cognitive Test } & \multicolumn{2}{c}{$\begin{array}{c}\text { Dehydrated } \\
(\mathbf{n = 1 2 3})\end{array}$} & \multicolumn{2}{c}{$\begin{array}{c}\text { Hydrated } \\
(\mathbf{n = 5 7})\end{array}$} & \multirow{2}{*}{ p value } \\
\cline { 3 - 6 } & & \multicolumn{1}{c}{ Mean } & \multicolumn{1}{c}{ SD } & \multicolumn{1}{c}{ Mean } & \multicolumn{1}{c}{ SD } & \\
\hline \hline Visual Attention & Letter cancellation & 21.03 & 6.123 & 35.35 & 2.322 & $<0.001$ \\
& Direct Image difference & 5.73 & 1.650 & 6.77 & 3.306 & 0.025 \\
\hline Visual memory & Indirect Image difference & 4.54 & 1.876 & 6.15 & 4.173 & 0.006 \\
\hline Short-term memory & Forward number recall total & 5.55 & 1.735 & 6.43 & 3.357 & 0.059 \\
& Reverse number recall & 4.61 & 1.965 & 5.08 & 3.300 & 0.303 \\
\hline Mathematical & Adding numbers & 33.10 & 15.750 & 37.35 & 21.991 & 0.183 \\
\hline Cognition & Line trace & 20.36 & 2.805 & 23.10 & 6.537 & 0.003 \\
\hline Visuomotor skills & & & &
\end{tabular}

Drinking water structure of the school

The school had one large water basin with three fountain taps. It was overcrowded with children in the break time as they weren't proportion to the number of students which were approximately 1000 students. The location was inconvenient as it was beside the toilets. It wasn't properly maintained where two taps only were functioning. It wasn't well cleaned, the basins were not adequately drained filled with stagnant water, there was growing molds and floating particles. This discouraged the students from drinking water at school.

\section{Focus Group Discussion}

The teachers claimed that the taps were looking "disgusting" and perceived them to be unsanitary and the water quality not adequate for school setting. They didn't know about any existed protocols for the cleaning and maintenance of water system at school, however they reported that there were no sufficient resources for maintenance of water sources. They had concerns about probability of tap water contamination and most of them were preferring to have cold water sources or provision of filters. Teachers indicated that there was a need for water education at school to encourage the students about drinking water and provide them with health and safety messages as students were unaware of their hydration status and how drinking water is 
important. In the break time most of the students drink beverages and soft sweaty

drinks and instead of drinking water. They didn't bring water bottles with them from

Table 3: Correlation between urine osmolality and cognitive function tests scores

\begin{tabular}{|c|c|c|c|c|c|c|c|c|c|}
\hline \multirow{2}{*}{\multicolumn{2}{|c|}{$\begin{array}{c}\text { Cognitive } \\
\text { function tests }\end{array}$}} & \multicolumn{2}{|c|}{ Visual Attention } & \multirow{2}{*}{$\frac{\begin{array}{c}\text { Visual } \\
\text { memory }\end{array}}{\text { IID }}$} & \multicolumn{2}{|c|}{$\begin{array}{c}\text { Short-term } \\
\text { memory }\end{array}$} & \multirow{2}{*}{\multicolumn{2}{|c|}{$\begin{array}{c}\begin{array}{c}\text { Mathematical } \\
\text { Cognition }\end{array} \\
\text { Adding } \\
\text { numbers } \\
\end{array}$}} & \multirow{2}{*}{$\begin{array}{c}\text { Visuomotor } \\
\text { skills }\end{array}$} \\
\hline & & LC & DID & & FNR & RNR & & & \\
\hline UO & $\mathbf{r}_{\mathbf{p}}$ & $-0.773^{* *}$ & $-0.154^{*}$ & -0.123 & $-0.165^{*}$ & -0.009 & $-0 .($ & & $-0.386^{* *}$ \\
\hline & $P$ value & $<0.001$ & .036 & .095 & .024 & .907 & .45 & & $<0.001$ \\
\hline \multicolumn{10}{|c|}{$\begin{array}{l}\text { UO=Urine Osmolality, } L C=\text { Letter cancellation, DID=Direct Image difference, IID=Indirect Image difference, } \\
F N R=\text { Forward number recall, RNR=Reverse Number recall, } r_{p}=\text { Pearson Correlation } * * \text { Correlation is } \\
\text { significant at the }<0.001 \text { level }(2 \text {-tailed). } \\
\text { Table4: Score of cognitive function tests before and after health education }\end{array}$} \\
\hline \multirow{2}{*}{\multicolumn{5}{|c|}{ Cognitive test }} & \multicolumn{2}{|c|}{$\begin{array}{c}\text { Before } \\
(\mathrm{n}=180)\end{array}$} & \multicolumn{2}{|c|}{$\begin{array}{c}\begin{array}{c}\text { After } \\
(\mathrm{n}=180)\end{array} \\
\end{array}$} & \multirow[t]{2}{*}{$P$ value } \\
\hline & & & & & Mean & SD & Mean & SD & \\
\hline \multirow{2}{*}{\multicolumn{2}{|c|}{ Visual Attention }} & \multicolumn{3}{|c|}{ Letter cancellation } & 25.13 & 8.389 & 25.43 & 9.854 & .030 \\
\hline & & \multicolumn{3}{|c|}{$\begin{array}{l}\text { Indirect Image } \\
\text { difference }\end{array}$} & 6.06 & 2.35 & 6.53 & 3.63 & .584 \\
\hline \multicolumn{2}{|c|}{ Visual memory } & \multicolumn{3}{|c|}{$\begin{array}{l}\text { Direct Image } \\
\text { difference }\end{array}$} & 5.06 & 2.91 & 6.29 & 3.58 & .003 \\
\hline \multirow{2}{*}{\multicolumn{2}{|c|}{ Short-term memo }} & \multicolumn{3}{|c|}{$\begin{array}{l}\text { Forward number } \\
\text { recall total }\end{array}$} & 5.80 & 2.43 & 4.85 & 3.34 & $<0.001$ \\
\hline & & \multicolumn{3}{|c|}{ Reverse number recall } & 4.73 & 2.49 & 5.20 & 2.51 & .327 \\
\hline \multicolumn{2}{|c|}{$\begin{array}{l}\text { Mathematical } \\
\text { Cognition }\end{array}$} & \multicolumn{3}{|c|}{ Adding numbers } & 34.28 & 18.16 & 40.13 & 20.59 & .018 \\
\hline \multicolumn{2}{|c|}{ Visuomotor skills } & \multicolumn{3}{|c|}{ Line trace } & 21.13 & 4.77 & 23.44 & 20.17 & .224 \\
\hline
\end{tabular}

*significant when $\mathrm{p}(<0.001)$

home and rarely go to drink water in the time between the lectures. Students were categorized into dehydrated and hydrated groups based on urine osmolality. Calculation of the mean scores of cognitive function tests for the two groups showed that the performance of the hydrated was better than dehydrated group. An independent $\mathrm{t}$ - test was performed to test for the significant difference between the two groups. In visual attention and visual memory tests the mean scores of letter cancellation, direct and indirect image difference was significant higher among the hydrated group $\mathrm{p}<0.001, \mathrm{p}=0.025$ and $\mathrm{p}=0.006$ respectively. Also for visuomotor skills the depicted difference for line trace test mean score was significant $\mathrm{p}=0.003$. On the other hand difference in the mean scores of short term memory and mathematical cognition tests wasn't shown to be significant.

*significant when $\mathrm{p}(<0.001)$

In Table 3 the correlation analysis showed a statistically significant negative correlation between urine osmolality and visual attention tests, where in letter cancelation $(r=-0.773$, $\mathrm{p}<0.001)$ and direct image difference $(\mathrm{r}=-0.154$, $\mathrm{p}=0.036$ ). There was identified statistically significant negative correlation between urine 
osmolality with forward number recall assessing short term memory ( $\mathrm{r}=-0.165$, $\mathrm{p}=0.024)$. Statistically significant negative correlations were also depicted between urine osmolality and visiumotor skills assessed by line trace test $(\mathrm{r}=-0.386, \mathrm{p}<0.001)$.

Analysis of the mean scores of cognitive function tests before and after implementation of health education showed improved performance. The increased mean score of letter cancelation test assessing visual attention from $25.13 \pm 8.38$ to $25.43 \pm 9.85$ was significant (paired t-test, $\mathrm{p}=0.30$ ).Regarding visual memory the increase in the mean score of direct image difference from $5.06 \pm 2.9$ to $6.29 \pm 3.58$ was significant $(\mathrm{P}=0.003)$. There was significant increase in the mean score of forward number recall assessing short term memory from $5.80 \pm 2.43$ to $4.85 \pm 3.34$ $(p<0.001)$. Also in Visumotor skills the mean difference in the scores of adding numbers test from $34.28 \pm 18.16$ to $40.13 \pm 20.59$ was significant $\mathrm{P}=0.18$. Changes in the scores of the cognitive function tests in both groups are shown in Table 4. The Mean urine

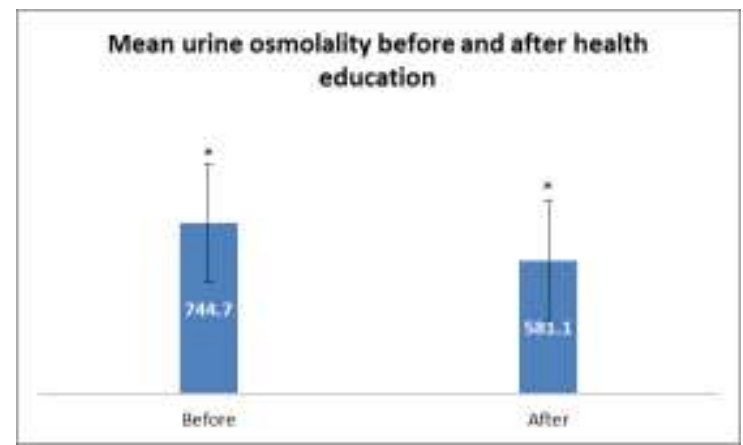

osmolality *significant when $p(<<0.001)$

Figure 2: Mean urine osmolality before and after health education

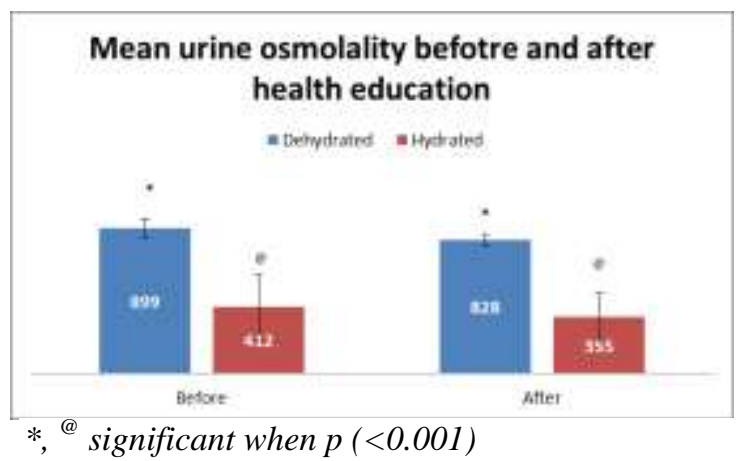

The Egyptian Journal of Community Medicine
Figure 3: Mean urine osmolality before and after health education in both dehydrated and hydrated groups.

of the students was $744.7 \pm 257.9 \mathrm{mosm} / \mathrm{kg}$ and it was significantly reduced after the health education provided to the students

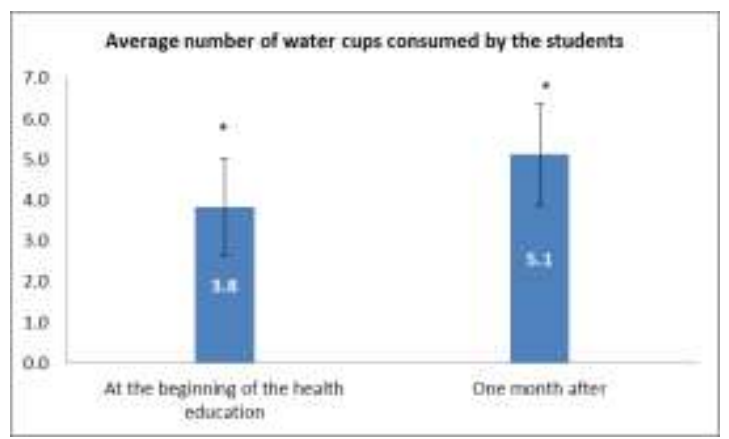

Figure 4: The average number of water cups consumed by the student at the beginning of health education and one month after.

and became $581.1 \pm 260.7 \quad \mathrm{mosm} / \mathrm{kg}$ $\mathrm{p}(<<0.001)$.

The figure shows that the mean urine osmolality was $899 \pm 59.4 \mathrm{mosm} / \mathrm{kg}$ in dehydrated and $412 \pm 199 \mathrm{mosm} / \mathrm{kg}$ in the hydrated students. A significant reduction in urine osmolality was detected in both dehydrated and hydrated students after health education to be $828 \pm 38.3 \mathrm{mosm} / \mathrm{kg}$ and $355 \pm 146.5 \mathrm{mosm} / \mathrm{kg}$ respectively $\mathrm{p}$ $(<0.001)$.

As shown in Figure 4 the average number of water cups the students consumed daily, was significantly increased from $3.8 \pm 1.18$ at the beginning of health education to reach $5.1 \pm 1.23$ after one month of health education.

\section{Discussion}

The aim of the study was to determine the prevalence of dehydration among the school students and impact of hydration status on the cognitive function. The study also examined the impact of health education on the students' drinking behavior and hydration status. It was found that $68.3 \%$ of the students were 
dehydrated; their urine osmolality was above $800 \mathrm{mosm} / \mathrm{kg} \mathrm{H} 2 \mathrm{O}$. There was shown a prevalence of dehydration among school aged children in many countrie. $^{22}$ In USA More than half of the students aged 6-10 years were dehydrated. ${ }^{39}$ Sixty three percent of children In Los Angeles and 66\% in York City had urine osmolality above 800 mosmol $/ \mathrm{kg}$. ${ }^{7}$ In France a study reported that $62 \%$ of $9-11$ years old children their urine osmolality was above 800 $\mathrm{mosmol} / \mathrm{kg}$ and $22.7 \%$ was above 1.000 mosmol $/ \mathrm{kg}{ }^{22}$. The estimated prevalence in the current study was attributed to inadequate drinking of plain water. It was shown that the students spent hours without a single drink, or drink less than they need. Students didn't know the importance of drinking water or the amount they should drink daily. Moreover improper location and poor maintenance of water system discouraged the students from drinking water. That was confirming to other studies where insufficient number, unsuitable location and improper maintenance of drinking water facilities discouraged the students from drinking water. ${ }^{29-31}$ In addition the opportunity to drink water was only in the break time this was creating crowdedness and many students didn't have a chance to drink. Students take money from their parent which wasn't enough to buy both beverages and bottled water so they prefer to buy beverages due its appealing taste and color and that exacerbate the dehydration. Studies depicted that the increased trend in beverages consumption especially in elementary schools is alarming. ${ }^{34}$ Same as a study done in USA found that water intake represented $33 \%$ of total fluid intake and the remaining intake was from beverages ${ }^{32}$.

In the current study it was determined that the school didn't provide drinking water guidance to the students .There was no policy for drinking water hygiene standards, availability of sugary beverages, accessibility and maintenance of water facilities or their number per student. After provision of health education there was significant decrease in students' urine osmolality. Percentage of dehydrated students was significantly decreased to reach $47.2 \%$ and nearly half of the students $52.8 \%$ became hydrated. This could be attributed to the depicted improvement in drinking water behavior among the students and increased in average number of water cups they consumed daily. That was confirming to other studies which showed that health education interventions was effective in increasing water consumption. ${ }^{33,34,35}$

Although Studies found that cognitive performance was impaired by dehydration ${ }^{13}$ and drinking water improve the cognitive function among the students $^{12,24,25}$ yet by reviewing the literature it was found few studies in that issue especially in adolescent and children. Fluid consumption is related to the levels of vasopressin in brain which has positive effect on memory and also the level of glycerol which supply glucose to CNS and improve cognitive function ${ }^{14}$. The level of cortisol increase with dehydration, it has negative impact on explicit memory, and thinking tasks ${ }^{8}$.

It was found in the current study a significant negative correlation between urine osmolality and the mean scores of some cognitive function tests, and the mean average scores of the hydrated students was significantly higher than dehydrated. The results of the study was similar to findings in previous researches showing a significant negative effects of dehydration on short term memory. ${ }^{12,13}$ Other studies found significant improvements in cognitive abilities after 
water provision as visual attention, memory, search and memory 12,14,28. Edmonds found that letter cancelation test was sensitive to dehydration ${ }^{35}$.

Same as David et al Study done in Israel among school students they divided them into hydrated and dehydrated according to urine osmolality and conducted five cognitive function tests. It was shown that the performance of hydrated was better than dehydrated .The scores of the short term memory tests were significantly higher among hydrated. ${ }^{13}$

The current study showed improvement of the students' hydration status after health education that was reflected on their mean scores of cognitive function tests when compared to their scores before health education. A study called "brain hydration conducted in primary school in Edinburgh." 36 The Students were educated to drink water between as well as during the lessons. The students became more concentrating, settled, and increased readiness to learn. Moreover, the school exceeded its national tests targets. ${ }^{37} \mathrm{~A}$ Soda-Free Summer Campaign was conducted in California, using health education materials in the form of coloring pages, activity worksheets, and books distributed in child facilities. ${ }^{38}$ It was reported that approximately half of individuals who received the materials were drinking less sugary beverages and sports drinks since the campaign. ${ }^{38}$

\section{Conclusion}

Dehydration is prevalent among school children and has negative impact on cognitive function. Raising the awareness of the students about importance of drinking water can positively change their behavior. Improving water accessibility in schools and developing educational, campaigns and promotional activities in collaboration with parents and school staff is proper direction that improves drinking water behavior among the students. Also schools have to implement drinking water polices and rules.

Study limitations: The study lacked interviewing the parents about the students' background information and determinant factors of cognitive ability test. These included developmental history, academic ability, medical issues, family relationships, and issues raised by the parents. That could help in gathering a holistic picture the child's environment.

There was control group and the improvement of students' performance in the post test may be attributed to the effect of memorizing the pretest.

Assessing of the students drinking behavior was done one time. There were no follow up to assess the long term effect of the health education on behavior adoption of the students.

The respondents were only 9-11 years in primary school Giza governorate selected with non-probability sampling so generalizability of the results will not be possible .There is a need for assessing the hydration status among different grades and comparing different types of schools with various infrastructures in other governorates, also in different seasons of the year.

\section{Recommendations}

It is recommended to extend the health education to parents as children depend on their care parents who motivate them to drink water. Further studies recommended to be done to assess the amount of water that affects the cognitive performance.It is also recommended to implement neuroimaging studies to identify the underlying neural changes that occur is with dehydration and hydration states.

\section{References}

No. 2

April

2021 
1. Popkin BM, D'Anci KE, Rosenberg IH. Water, hydration, and health. Nutr Rev. 2010;68(8):439-458. doi:10.1111/j.17534887.2010.00304.

2. Gouda Z, Zarea M, El-Hennawy U, et al. Hydration Deficit in 9- to 11-Year-Old Egyptian Children. Glob Pediatr Health. 2015;2:2333794X15611786. Published 2015 Oct 6. doi:10.1177/2333794X15611786

3. Institute of Medicine of National Academies. Dietary Reference Intake ]: The Essential Guide to Nutrients Requirements. Washington DC: Institute of Medicine of National Academies; 2006.

4. EFSA Panel on Dietetic Products Nutrition and Allergies. Scientific opinion on dietary reference values for water. EFSA J. 2010; 8:1459-1507.

5. 5-St-Onge MP, Keller KL, Heymsfield SB. Changes in childhood food consumption patterns: a cause for concern in light of increasing body weights. Am J Clin Nutr. 2003 Dec; 78(6): 1068-73.

6. 7- Polycarpe E, Arnould L, Schmitt E, Duvillard L, et al. Low urine osmolality as a determinant of cisplatin-induced nephrotoxicity. Int J Cancer .2004; 111:131137.

7. Stookey JD, Brass B, Holliday A, Arieff A. What is the cell hydration status of healthy children in the USA? Preliminary data on urine osmolality and water intake. Public Health Nutr. 2012;15:2148-2156. doi:10.1017/S1368980011003648.

8. de Souza-Talarico JN, Marin MF, Sindi S, Lupien SJ. Effects of stress hormones on the brain and cognition: Evidence from normal to pathological aging. Dement Neuropsychol. 2011;5(1):8-16. doi:10.1590/S1980-

\section{DN05010003}

9. Kaushik A, Mullee MA, Bryant TN, Hill CM. A study of the association between children's access to drinking water in primary schools and their fluid intake: can water be "cool" in school? Child Care Heal Dev. 2007; 33:409-415.

10.El-Sabely AA, Tork H, El-Sayid Hussien Y. Comparative study of nutritional status and dietary habits of children from public and private primary schools in Zagazig City, Egypt. J Nurs Heal Sci. 2006;3:47-52.

11.Anigilaje EA. Management of Diarrheal Dehydration in Childhood: A Review for Clinicians in Developing Countries. Front Pediatr. 2018; 6:28. Published 2018 Feb 23. doi:10.3389/fped.2018.00028

12.Edmonds CJ, Jeffes B. Does having a drink help you think? 6-7-Year-old children show improvements in cognitive performance from baseline to test after having a drink of water. Appetite. 2009; 53(3):469-72. 10.1016/j.appet.2009.10.002

13. Bar-David Y, Urkin J, Kozminsky ELY. The effect of voluntary dehydration on cognitive functions of elementary school children. Acta Pædiatrica. 2005; 94(11):166773. $10.1080 / 08035250500254670$

14. Cian C, Koulmann N, Barraud PA, Raphel C, Jimenez C, Melin B. Influence of variations in body hydration on cognitive function: effect of hyperhydration, heat stress and exercise induced dehydration. J Psychophysiol2000; 14:29-36.

15. Oria RB, Patrick PD, Zhang $\mathrm{H}$, et al. APOE4 protects the cognitive development in children with heavy diarrhea burdens in northeast Brazil. Ped Res. 2005; 57:310-316.

16.Trinies V., Chard A.N., Mateo T., Freeman M.C. Effects of Water Provision and Hydration on Cognitive Function among Primary-School Pupils in Zambia: A Randomized Trial. PLoS ONE. 2016;11:e0150071. doi: 10.1371/journal.pone.0150071

17.Levine S, Saltzman A, Katof B, Meister A, CooperTB. Proliferation of glial cells induced by lithium in the neural lobe of the rat pituitary is enhanced by dehydration. Cell Prolif. 2002; $35: 167-172$

18.Sonneville KR, Long MW, Rifas-Shiman SL, Kleinman K, Gillman MW, Taveras EM. Juice and water intake in infancy and later beverage intake and adiposity: could juice be a gateway drink? Obesity (Silver Spring). 2015 Jan; 23(1):170-6.

19.Muñoz CX, Johnson EC, McKenzie AL, Guelinckx I, Graverholt G, Casa DJ, et al. Habitual total water intake and dimensions of 
mood in healthy young women. Appetite. 2015 Sep;92:81-6.

20.Michels N, Van den Bussche K, Vande Walle J, De Henauw S. School Policy on Drinking and Toilets: Weaknesses and Relation With Children's Hydration Status. J Nutr Educ Behav. 2019 Jan;51(1):32-40.

21.Bottin J, H, Morin C, Guelinckx I, Perrier E, T: Hydration in Children: What Do We Know and Why Does it Matter? Ann Nutr Metab 2019; 74(suppl 3):11-18. doi: $10.1159 / 000500340$

22.Bonnet F, Lepicard EM, Cathrin L, et al. French children start their school day with a hydration deficit. Ann Nutr Metab. 2012;60:257-263. doi:10.1159/000337939.

23. Wahba SA, Mekawy A, Ahmed R, Mohsen W. Breakfast skipping and dietary adequacy of primary school children in Cairo. J Appl Sci Res. 2006;2:51-57

24.Benton D, Burgess N. The effect of the consumption of water on the memory and attention of children. Appetite. 2009;53(1):143-6.

10.1016/j.appet.2009.05.006

25.Kenney EL, Gortmaker SL, Carter JE, Howe MCW, Reiner ,JF Cradock AL,.Grab a Cup, Fill It Up!An Intervention to Promote the Convenience of Drinking Water and Increase Student Water Consumption During School Lunch. Am. J. Public Health 2015; 105, 17771783.

26. Sahay M, Sahay R. Hyponatremia: A practical approach. Indian J Endocrinol Metab. 2014; 18(6):760-771. doi:10.4103/22308210.141320

27.Perrier ET, Buendia-Jimenez I, Vecchio M, Armstrong LE, Tack I\& Klein A. TwentyFour-Hour Urine Osmolality as a Physiological Index of Adequate Water Intake. Disease Markers. 2015;1-8. doi:10.1155/2015/231063

28.Edmonds CJ, Burford D. Should children drink more water?: The effects of drinking water on cognition in children. Appetite. 2009;52(3):776-9.

10.1016/j.appet.2009.02.010

29. Patel AI, Bogart LM, Uyeda KE, Rabin A, Schuster MA. Perceptions about availability and adequacy of drinking water in a large
California school district. Prev Chronic Dis. 2010;7(2):A39.

30.Northcoast Nutrition and Fitness Collaborative. Water woes. Available at: http://www.northcoastnutrition.org/media/fi les/Water\%20Woes_for\%20web\%5b1\%5d.pdf 31.Patel AI, Bogart LM, Uyeda KE, Martinez H, Knizewski R, Ryan GW, Schuster MA .School site visits for community-based participatory research on healthy eating. Am J Prev Med. 2009 Dec; 37(6 Suppl 1):S300-6 32. Turner L, Chaloupka FJ .Wide availability of high-calorie beverages in US elementary schools.Arch Pediatr Adolesc Med. 2011 Mar; 165(3):223-8.

33.Fadda R, Rapinett G, Grathwohl D, Parisi M, Fanari R, Calo CM, et al. Effects of drinking supplementary water at school on cognitive performance in children. Appetite. 2012;59(3):730-7. Epub 2012/07/31. 10.1016/j.appet.2012.07.005

34.Visscher TL, van Hal WC, Blokdijk L, Seidell JC, Renders CM, Bemelmans WJ. Feasibility and impact of placing water coolers on sales of sugar-sweetened beverages in Dutch secondary school canteens.Obes Facts. 2010; 3(2):109-15.

35. Edmonds $\mathrm{C}$. The effect of water consumption on cognitive performance. Appetite.2012;59(2), 624. doi:10.1016/j.appet.2012.05.056

36 .Yorkshire water launches "cool schools" campaign. Available at URL: http://www.yorkshirewater.com/popup/schools /htm.

37.Water improves school test results. Available at URL. http://newsbbc.co.u Wl/hlleducation/728017.sun.

38. Bay Area Nutrition and Physical Activity Collaborative Soda Free Summer Campaign. Available at: http://www.banpac.org/ resources_sugar_savvy.htm

39.Kenney EL, Long MW, Cradock AL, Gortmaker SL. Prevalence of inadequate hydration among US children and disparities by gender and race/ethnicity: National Health and nutrition examination survey, 20092012. Am J Public Health. 2015;105(8):e113e118. doi: 10.2105/AJPH.2015.302572.

No. 2

April

2021 
40.Jirout J, LoCasale-Crouch J, Turnbull K, et al. How Lifestyle Factors Affect Cognitive and Executive Function and the Ability to Learn in Children. Nutrients. 2019;11(8):1953. Published $2019 \quad$ Aug 20. doi:10.3390/nu1108195

41. Gopinathan, PM, Pichan, G \& Sharma, V ( 1988) Role of dehydration in heat stressinduced variations in mental performance. Arch Environ Heal 43, 15-17. 42.Pawson, C, Gardner, MR, Doherty, S, et al. (2013) Drink availability is associated with enhanced examination performance in adults. Psychol Teach Rev 19, 57-67. 